\title{
Aportes teóricos para la construcción de una ley de seguridad y defensa nacional en Colombia: aprendiendo de otros Estados ${ }^{1}$
}

https://doi.org/10.21830/9789585350601.05

\author{
Martha Lucía Bahamón Jara \\ Wisman Johan Díaz Castillo ${ }^{3}$ \\ Ximena A. Cujabante Villamil ${ }^{4}$ \\ Universidad Militar Nueva Granada \\ Manuel Alexánder Betancur Montoyas \\ Escuela Militar de Cadetes "General José María Córdova"
}

1 Este capítulo es producto de investigación del proyecto INV-EES 2975 de 2019 "El panorama del post conflicto en Colombia: un acercamiento desde la gobernanza y la reforma del sector seguridad", financiado por la Universidad Militar Nueva Granada. Se reconoce la participación de la Universidad del Rosario en el marco del Convenio Especial de Cooperación con la Universidad Militar Nueva Granada.

2 Abogada de la Universidad Libre de Colombia, especialista en Derecho Administrativo de la Universidad Santo Tomás y magíster en Defensa de los Derechos Humanos y Derecho Internacional Humanitario. Exvicerrectora académica de la Universidad Militar Nueva Granada en el periodo 20092015. Directora de Posgrados de la Facultad de Relaciones Internacionales, Estrategia y Seguridad. Docente tiempo completo de carrera. Asesora y consultora de instituciones de educación superior. ORCID: https://orcid.org/0000-0002-5877-6886. Contacto: martha.bahamon@unimilitar.edu.co

3 Profesional en Derecho de la Fundación Universitaria Agraria de Colombia y especialista en Derecho Administrativo de la Universidad Santo Tomás. Materias finalizadas en la Maestría en Derecho Administrativo de la Universidad Santo Tomás. OrCID: https://orcid.org/0000-0001-6370-1945. Contacto: wisman.diaz@uniagraria.edu.co

4 Politóloga de la Universidad Javeriana, especialista en Negociación y Relaciones Internacionales de la Universidad de los Andes, magíster en Asuntos Internacionales y doctora en Estudios Políticos de la Universidad Externado de Colombia. Docente de tiempo completo de la Facultad de Relaciones Internacionales, Estrategia y Seguridad de la Universidad Militar Nueva Granada. Orcid: https://orcid. org/0000-0002-5473-163X. Contacto: ximena.cujabante@unimilitar.edu.co

5 Magister en Estudios Políticos e Internacionales, Universidad del Rosario. Profesional en Relaciones Internacionales y Estudios Políticos, Universidad Militar Nueva Granada. Profesional en Ciencias Militares, Escuela Militar de Cadetes "General José María Córdova”. OrciD: https://orcid.org/0000-00016511-9000 


\section{Resumen}

El presente capítulo tiene como objetivo presentar insumos conceptuales para consolidar una ley (instrumento jurídico) de seguridad y defensa para Colombia, para lo cual se analizan los casos de países de la región que cuentan con este tipo de instrumento y cómo se puede aprovechar su experiencia para construirlo en el país. Siguiendo una metodología deductiva y con base en un análisis cualitativo de la información obtenida en el rastreo de fuentes bibliográficas, se consolidan las características comunes de los países estudiados que deben ser contempladas en el caso colombiano: los interés nacionales, el uso total de medios y las capacidades con las cuales cuenta el Estado.

Palabras clave: Colombia; defensa; Latinoamérica; ley; libro blanco; seguridad.

\section{Introducción}

Este capítulo tiene como objetivo presentar los componentes que se deberían regular debidamente para establecer la ley de seguridad y defensa de Colombia. Este tipo de regulación es importante porque la seguridad es un fin del Estado y para alcanzarlo se necesita un cuerpo normativo que dé cuenta de los intereses nacionales estipulados en la Constitución y que son el objeto de protección de la seguridad. Por lo tanto, esta normatividad no solo tiene que enunciar cuáles instituciones están relacionadas necesariamente con este objetivo, sino además definir los insumos que deben utilizar los niveles estratégicos para alcanzar los fines del Estado. Este contenido jurídico se conoce normalmente como ley o libro blanco de defensa.

En la actualidad Colombia carece de un lineamiento de esta naturaleza, a diferencia de otros países latinoamericanos como Brasil, Chile y Argentina. Precisamente, estos últimos se seleccionaron como casos de estudio porque cumplen con los siguientes criterios: (1) tienen un cuerpo normativo que regula el tema de la seguridad y la defensa nacional (2) producto de un proceso de transición y (3) las Fuerzas Militares tienen una participación relevante en su desarrollo como nación. Estos criterios fueron elegidos de cara a los procesos de reforma del sector seguridad que actualmente vive el país y, por lo tanto, evidencian la importancia de esta investigación.

El proceso de implementación de los acuerdos de paz con las FARC-Ep, las nuevas demandas sociales expresadas por la ciudadanía y la presencia de 
nuevos actores ilegales que buscan el dominio de las economías ilícitas de las regiones que fueron afectadas en mayor medida por el conflicto armado hacen que Colombia tenga actualmente un escenario complejo en materia de seguridad. Como consecuencia, la convergencia de las amenazas en los territorios y los diferentes fenómenos criminales que se generan en este contexto hacen necesario realizar un cuidadoso análisis sobre la manera como el Estado colombiano debería emplear su fuerza — no solamente la militar — para abordar y mitigar los complejos escenarios de seguridad que se presentan.

Las amenazas actuales a la seguridad, por sus características transnacionales, representan un reto importante para las capacidades de los Estados porque estos no han logrado consolidarse efectivamente a lo largo de sus territorios. En tal sentido, esta compleja situación demanda repensar la manera como se tienen que abordar las amenazas crecientes y cambiantes, para lo cual es fundamental reconocer que las fuerzas de seguridad del Estado (Fuerzas Militares y de Policía) no se deben considerar como las únicas representantes de la estatalidad en las regiones más afectadas por el conflicto. Por el contrario, es necesario comprender que la presencia integral de la institucionalidad es crucial para garantizar los derechos de las comunidades y prestar los servicios básicos a las poblaciones. Precisamente por estas razones, es indispensable generar un contenido normativo que facilite y guíe el cumplimiento de dichos objetivos.

Este cuerpo normativo se expresa en lo que se conoce como una ley de seguridad y defensa o libro blanco, en la cual se establecen los diferentes medios con los que cuenta un Estado para salvaguardar sus intereses en materia de seguridad y defensa, al tiempo que permite desarrollar las estrategias para defenderlos. Vale la pena mencionar que una ley de seguridad y defensa no tiene en cuenta exclusivamente a la fuerza pública, sino que integra de manera coordinada y articulada al resto de la institucionalidad del Estado que, de algún modo u otro, tiene responsabilidades relativas al mantenimiento y garantía de la seguridad y defensa de la nación.

Para comprender el contenido de una ley como esta primero se debe mencionar que en los ordenamientos jurídicos de los países existe una jerarquía piramidal de las normas. Según esta organización, la ley de seguridad y defensa se encuentra en un segundo nivel, en el cual se regulan los mandatos constitucionales sobre las materias que están en un nivel superior. Esta regu- 
lación tiene como objeto otorgar los insumos necesarios para el uso de todos los medios con los cuales cuenta el Estado y, de esta forma, mitigar adecuadamente las amenazas.

Asimismo, se debe considerar que la ausencia de una normatividad clara en referencia a la seguridad y defensa nacional del país no solo dificulta la planificación estratégica, sino que también impide la consolidación de todas las capacidades del Estado para mitigar, de manera adecuada, la convergencia de amenazas que se presentan en las regiones donde no ha afianzado su presencia, como se mencionó en párrafos anteriores.

Lo anterior da pie a la pregunta de investigación: ¿Cuáles son los componentes jurídicos que deben integrar la ley de seguridad y defensa de Colombia con el fin de afrontar los retos generados por el escenario de seguridad en el país y así garantizar el uso adecuado y legítimo de la fuerza? A continuación, para abordar este interrogante se hace un análisis de la seguridad como objeto del derecho y se estudian las diferentes formas en que otros países con problemáticas similares han generado este contenido normativo.

\section{Marco teórico}

El sustento teórico del presente capítulo es la teoría jurídica propuesta por Dworkin, para quien el ordenamiento jurídico no solo está integrado por reglas o normas jurídicas, sino que para desarrollarlo se hace necesario usar principios que respondan con claridad a las demandas de cada sociedad. En este sentido, se debe considerar que,

para Dworkin, el derecho consiste en la mejor interpretación argumentativa que justifique y comprenda en su totalidad el sistema jurídico, cuyos argumentos en los tribunales de justicia son inevitablemente cuestiones relativas a las convicciones morales y políticas de los jueces, dado que es parte de su función interpretativa. (Rosas, 2019, p. 8)

Específicamente, este trabajo hace referencia al ordenamiento jurídico que se constituye en favor de la seguridad y defensa nacional. Según esta teoría, tal ordenamiento estaría compuesto por las reglas y los principios que se desarrollan en materia de seguridad y defensa, los cuales serán elaborados con base en el análisis de la situación en Brasil, Chile y Argentina. 


\section{Método}

En este trabajo se empleó una metodología de investigación deductiva y se implementó una técnica de recolección de fuentes bibliográficas para establecer los conceptos relacionados con la seguridad y la defensa, rastrear las formas mediante las cuales se ha regulado esta temática en países con fenómenos similares — como Brasil, Chile y Argentina- y derivar las lecciones aprendidas de los países centroamericanos. Estos referentes se analizaron cualitativamente con el método de estudio de caso, que en términos del profesor Eisenhardt (1989) es una "una estrategia de investigación dirigida a comprender las dinámicas presentes", tal y como se presenta en este capítulo.

\section{Resultados}

\section{Análisis de la seguridad y defensa desde la perspectiva del derecho}

La primera variable que se debe considerar es la seguridad y defensa como un objeto del derecho. En este sentido, es necesario comenzar por la propia definición de derecho para comprender el contenido jurídico de la seguridad y la defensa: se entiende por derecho el conjunto normativo que regula los efectos externos de las interacciones entre los actores de una sociedad, entre los cuales se encuentra el propio Estado. De este modo, para determinar el contenido de la seguridad y la defensa como objeto del derecho es importante establecer tanto los actores que participan como los efectos externos. En este caso, el Estado constituye el principal actor, mientras que sus efectos se relacionan con la capacidad que dispone para mitigar las amenazas que puedan afectar los intereses y fines de la nación.

Con base en lo anterior, para establecer el contenido regulatorio de la capacidad que tiene el Estado para mitigar dichas amenazas en Colombia se debe determinar, en primer lugar, cómo se realizará esta regulación y, por lo tanto, estudiar la jerarquía normativa del país. De acuerdo con el ordenamiento jurídico colombiano, la Constitución y las normas internacionales están a la cabeza y luego se encuentran las leyes que se encargan de desglosar los 
mandatos proferidos en el primer nivel. En consecuencia, la regulación de la seguridad y la defensa se realizará mediante la ley, dado que, como se mostrará a continuación, dentro de las normas internacionales y constitucionales en materia de seguridad y defensa se encuentran de forma general los mandatos y los intereses que el Estado debe proteger, sin particularizar o especificar las capacidades que tiene y que debe utilizar para mitigar las amenazas que se presentan en contra de estos fines, de manera que es función de la ley tipificar con claridad estas características.

En cuanto al nivel superior, se puede afirmar que las normas internacionales que han regulado la seguridad y la defensa tienen como objetivo mantener la paz mundial y la seguridad global. Esto deja claro cuáles son los intereses de la comunidad internacional, de modo que busca reglamentar el uso de la fuerza entre los Estados y establecer cada una de las conductas que deben seguir con el fin de mitigar las amenazas que afectan a todas las naciones.

Sobre los intereses de la comunidad internacional de garantizar y mantener la paz y la seguridad global, se puede traer a colación la Carta de San Francisco de 1945, donde se determina que tanto la seguridad global como la paz mundial son los fines que debe salvaguardar la Organización de las Naciones Unidas (ONU). Así mismo, establece las formas mediante las cuales se pueden proteger estos intereses, otorgando la facultad a la organización para proferir mandatos de paz que permitan a los Estados usar la fuerza en determinadas circunstancias.

Otro aspecto reglamentado por normas internacionales es la configuración de instrumentos jurídicos de este nivel que buscan mitigar las diferentes amenazas que afectan la seguridad y la paz. Entre estas se encuentran los tratados e instrumentos sobre el desarme preventivo, la prevención del genocidio, el desminado, el terrorismo, el tráfico ilícito de drogas, etc. Cada uno de estos fenómenos ha sido objeto de varias normas que buscan mitigar su efecto en el sistema internacional, de tal forma que se han establecido las conductas que deben realizar los Estados con el fin de afrontar dichas amenazas e incluso prohibir conductas que las favorezcan.

En materia constitucional, la seguridad tiene múltiples concepciones, en algunos casos entendida como un derecho y en otros como un servicio. Sin tomar en consideración estos dos enfoques, se encuentra que la Constitución establece que la seguridad está estrechamente relacionada con los fines del 
Estado, no solo por el mandato del artículo segundo constitucional, sino también por la concepción teórica que se tiene sobre el Estado: de acuerdo con la carta magna, en Colombia se sigue una corriente jurídica sobre el estado social de derecho que se fundamenta en la necesidad que tienen los individuos de contar con condiciones de seguridad mínimas para su desarrollo y bienestar. De este modo se entiende el artículo segundo de la Constitución de Colombia, que ordena la protección de los bienes y las libertades de las personas, la soberanía y el Estado constitucional.

En este sentido, se hace evidente que una premisa constitucional para el Estado colombiano es proteger y brindar seguridad a sus ciudadanos. Adicionalmente, ante los nuevos retos que presenta un mundo cada vez más globalizado y potenciado por la revolución de las telecomunicaciones, se evidencia que el Estado debe asegurar su propia existencia para cumplir con este propósito de protección, de manera que el objeto de seguridad no solo es la ciudadanía, sino también el Estado y, por ende, sus intereses nacionales.

Adicionalmente, se debe tener en cuenta que el derecho constitucional concibe la seguridad de dos formas: en primer lugar, la entiende como un derecho de los ciudadanos y, en segundo lugar, como un servicio a cargo del Estado. Desde la perspectiva de la seguridad como un derecho se encuentran aquellas circunstancias en las cuales el Estado garantiza y protege alguno de los elementos indispensables para mantener la dignidad de las personas, como es el caso de la seguridad alimentaria, la seguridad jurídica y, entre otros, la seguridad a la integridad de las personas, que también resulta ser un derecho en favor de los ciudadanos que se encarga al Estado para que mitigue cada una de las amenazas que lo afecten. Asimismo, lo anterior también permite comprender la perspectiva de la seguridad como servicio, pues el Estado debe utilizar cada una de sus capacidades para cumplir su misión de salvaguardar los diferentes derechos que establece el ordenamiento jurídico colombiano, para lo cual debe mitigar las amenazas que puedan afectarlos.

\section{Estudio de casos para comprender el contenido de la ley de seguridad y defensa nacional}

A continuación, se presentan los criterios que justifican la elección de los países del estudio de caso: (1) Estados que hayan desarrollado procesos de tran- 
sición, (2) que en su formación las Fuerzas Militares tengan un papel relevante y (3) que exista una ley o normatividad de seguridad y defensa. En ese sentido, los casos que cumplen estos criterios son Chile, Argentina y Brasil.

Además, se debe tener en cuenta que Colombia está actualmente en un nuevo escenario a raíz de la implementación del acuerdo de paz. Esto pone de presente que el proceso de transición es una de las características principales para determinar el contenido de la ley de seguridad y defensa para el país, circunstancia que se tuvo en cuenta en la selección de los casos.

Otro de los criterios considerados para la selección fue que existiera una estrecha relación entre las Fuerzas Militares y la construcción de Estado, pues a diferencia de otros países con un profundo contexto histórico en su formación como naciones, en Colombia es muy reciente el proceso de construcción de la república y el Estado. En este corto tiempo, las Fuerzas Militares han tenido una participación relevante e importante para la propia definición como Estado, por lo cual participan activamente en las interacciones de las comunidades, más aún si se considera que en muchas regiones del país son el único representante del Estado, por lo cual su vinculación con la sociedad es mucho más evidente. En consecuencia, se trata de un criterio de elección muy relevante que, junto con los descritos anteriormente, debían cumplir los casos en estudio, pues el análisis de sus normatividades permite sustraer los componentes para definir una regulación en Colombia.

\section{Estudio de caso: Chile}

El caso chileno es considerado en este análisis comparativo porque actualmente cuenta con un libro blanco de defensa y un libro blanco de política exterior, con el cual está interconectado y configura un contenido normativo sobre seguridad y defensa. Asimismo, la formación del Estado chileno, como en la mayoría de los países latinoamericanos, ha estado ampliamente influida por las Fuerzas Militares. Por último, atravesó un proceso de transición de la dictadura a la democracia.

\section{Proceso de transición}

A pesar de que la transición de Chile fue diferente a la de Colombia, en cuanto fue democrática, sigue siendo un proceso transicional como el que atraviesa Colombia y que mantiene una similitud en las amenazas que los afectan, parafraseando a los profesores Freer y Wehner (2018). 


\section{Importancia de las Fuerzas Militares para la consolidación como Estado}

De acuerdo con el profesor Díaz (2003), en el origen de la nación chilena se presentan múltiples fenómenos sociales que han determinado su construcción como nación, en los cuales las Fuerzas Militares sobresalen como un factor determinante, más aún si se tiene en consideración su desarrollo en el siglo XX, entre golpes de Estado y dictaduras que desembocaron en la actual estructura chilena. Díaz (2003) también argumenta que el país se ha formado desde la Conquista por medio de sus Fuerzas Militares: por una parte, en las confrontaciones contra los araucanos, su participación en el proceso de independencia siglos después y su papel en los dos conflictos internacionales que tuvo Chile con sus vecinos. Por otra parte, Díaz (2003) menciona su notable relevancia en los procesos sociales del siglo XX, que si bien tuvieron consecuencias negativas, igualmente forman parte de la consolidación del país. Por todo lo anterior, se puede considerar que las Fuerzas Militares chilenas han incidido en muchos momentos históricos claves para la estructuración del país.

\section{Contenido normativo en materia de seguridad y defensa nacional}

De manera similar a Colombia, la Constitución chilena establece que el mantenimiento de la seguridad nacional es un fin del Estado, para lo cual se sanciona que debe haber una participación armónica de cada una de las instituciones que lo conforman (Constitución de Chile, artículo primero, tercer párrafo). Los ministerios de Defensa y de Relaciones Exteriores interpretaron y desarrollaron de forma integral esta premisa con la creación del libro blanco de la Cancillería, denominado Política exterior de Chile 2030 y formulado en 2018, y el Libro blanco de defensa, expedido en el ańo 2017.

\section{Fundamento constitucional de la seguridad y la defensa nacional}

Una de las características comunes que tienen los instrumentos jurídicos de seguridad y defensa de los casos en estudio es la relación que establecen con los fundamentos constitucionales. Es decir, este contenido normativo se expresa como el desarrollo de los mandatos constitucionales de cada país, en los cuales también se definen los intereses y bienes que son objeto de protección, de tal manera que constituyen el primer elemento que se debe considerar al analizar los libros blancos de defensa. En el caso específico de Chile, 
esta normativa estipula que la seguridad nacional debe garantizar, por una parte, la propia supervivencia del Estado (el orden institucional republicano y democrático), y, por otra, la propia sociedad chilena. Además, son estos intereses y bienes los que definen la estructura tanto para la seguridad como para la defesa nacional.

Por consiguiente, estos intereses no solo ordenan la protección de los vínculos entre el Estado, la sociedad y la persona humana, sino además identificar las amenazas que los pueden afectar. Con esta claridad, a continuación se presentan las bases constitucionales que reglamentan la seguridad y la defensa en Chile: (1) resguardar la seguridad nacional, (2) dar protección a la población y a la familia, (3) propender al fortalecimiento de esta, (4) promover la integración armónica de todos los sectores de la nación y (5) asegurar el derecho de las personas a participar con igualdad de oportunidades en la vida nacional.

Cabe resaltar que estos fines son una evidencia de que el libro blanco chileno aplica los diferentes conceptos que se han desarrollado sobre seguridad en el hemisferio, pues entre estas finalidades constitucionales se encuentran matices de las diferentes evoluciones que ha tenido la seguridad, como la seguridad nacional y la seguridad humana. Esta característica del libro blanco chileno se debe a que no solo se procura asegurar la supervivencia del Estado, sino que además tiene como objetivo brindar bienestar a las personas, satisfaciendo sus derechos fundamentales y proveyendo los servicios públicos necesarios para su desarrollo.

\section{Regulación de la seguridad y la defensa nacional en Chile}

Además de las bases constitucionales que preceden, se debe mencionar que los contenidos normativos que sustentan la seguridad y defensa de Chile no están sintetizados en un solo instrumento (norma o ley), ya que las condiciones del actual sistema internacional hace necesario la interacción de diversos instrumentos que faciliten a los Estados contrarrestar las amenazas que puedan enfrentar.

Lo que se ha explicado hasta el momento evidencia que la normatividad chilena ha contemplado amenazas que forman parte de fenómenos locales e internacionales. Además, cuando define los criterios para establecer cuáles son 
estas amenazas hace un análisis claro de los componentes esenciales que garantizan su supervivencia como nación de cara a cada contexto posible, como el crimen organizado transnacional, el daño al medio ambiente, su posición sobre el océano Pacífico, los intereses de otras naciones y demás amenazas que puedan impedir su desarrollo.

A lo largo de este análisis sobre los instrumentos jurídicos del Estado chileno se ha encontrado, por una parte, que la Constitución establece los fundamentos que orientan los intereses de seguridad y defensa de la nación, $y$, por otra, que existe un libro blanco de defensa y un libro blanco de política exterior, los cuales se deben comprender de forma integral por cuanto regulan claramente los medios y las capacidades del Estado en materia de seguridad y defensa. Específicamente, este ordenamiento jurídico regula cada una de las capacidades con las cuales el Estado puede contribuir a mitigar las amenazas que se han identificado y alcanzar los intereses mencionados.

Estas capacidades se refieren a una mayor presencia institucional en la totalidad del territorio, lo cual se expresa en una política de ordenamiento territorial que define cada uno de los escenarios en donde pueden actuar las autoridades competentes con el fin de mitigar las amenazas que se presenten. De esta manera se facilita una comprensión clara de las particularidades de cada una de estas amenazas y, por consiguiente, se puede obtener el mayor provecho posible de estos insumos jurídicos.

Estos documentos presentan además una clara estructura del sector, en la cual no solo se caracteriza el contexto internacional de la defensa, donde se determina cuáles son los actores y fenómenos del sistema internacional que pueden tener injerencia en la nación, sino que también se establece la definición que tienen las fuerzas sobre la seguridad y defensa, de donde se pueden sustraer los objetivos de la defensa nacional. Así mismo, describen otras características de la seguridad y la defensa chilena, como el Sistema de Defensa Nacional, que está conformado por cada una de las entidades estatales que integran el sector defensa. Finalmente, estos documentos definen los lineamientos que se deben tener en cuenta para planear las estrategias de defensa, en las cuales se determina el uso de las capacidades y las características propias de las Fuerzas Militares. Cabe anotar que cada uno de estos lineamientos forma parte fundamental de la planeación estratégica. 
En cuanto a los postulados de política exterior, el libro blanco define los lineamientos que el Estado debe seguir en su relación con sus vecinos y demás naciones que forman parte del sistema internacional. Específicamente, señala que las actuaciones diplomáticas deben asegurar los elementos de la seguridad y la defensa, para lo cual deben analizar y trabajar los procesos regionales, la política exterior multilateral, los temas estratégicos y emergentes, así como la agenda comercial. Como se observa, con cada uno de estos aspectos se abordan las demandas actuales en materia de seguridad y defensa nacional con la lógica de la seguridad multidimensional.

En síntesis, el estudio de la organización jurídica chilena sobre la seguridad y la defensa evidencia que el Estado debe dejar sentadas las bases normativas en la Constitución, en cuanto norma jurídica que determina los postulados macro que se deben desarrollar en el segundo nivel de la jerarquía legislativa, que en este caso son los dos libros blancos. Así, a partir de estas bases constitucionales se debe regular cada una de las capacidades e instituciones del Estado, las cuales deben trabajar para mitigar las amenazas que afectan los intereses referidos en la norma constitucional, dentro del nivel legislativo. Para esto es importante reconocer el entorno regional e internacional del país y, de esta forma, estructurar el sector de seguridad y defensa permitiendo el uso de cada uno de los recursos necesarios para salvaguardar dichos intereses, sin olvidar que estos mismos intereses se deben proteger dentro del sistema internacional. Por ello, otro de los componentes normativos debe ser la regulación de la política exterior y sus capacidades de cara a alcanzar el mejor provecho de este sistema.

\section{Estudio de caso: Brasil}

En este análisis comparativo se consideró el caso de Brasil porque, como se mencionó en el numeral anterior, actualmente cuenta con un libro blanco de defensa, en el cual se configura el contenido normativo sobre seguridad y defensa. Asimismo, como en la mayoría de los países latinoamericanos, la formación del Estado brasileño ha sido ampliamente influida por las Fuerzas Militares. Por último, también pasó por un proceso de transición de la dictadura a la democracia, que es fundamental en el desarrollo del estado social de derecho. 


\section{Proceso de transición}

De acuerdo con los profesores Share y Mainwaring (1986), la transición en Brasil representa un hecho paradigmático por cuanto es una de las más prolongadas de la historia, pues, aunque el proceso de liberación del régimen autoritario militar empezó en 1974, la transición solo se consolidó hasta la elección de un presidente civil de oposición en 1985, es decir, más de una década después. Por lo tanto, los autores argumentan que la existencia de un proceso transicional en el Estado brasileńo ha incidido en su configuración actual, para lo cual muestran los cambios que este proceso generó y que siguen vigentes hoy en día.

Si bien Brasil pasó por un proceso de transición de una dictadora a un sistema democrático, este caso tiene elementos que son de gran valor jurídico para Colombia, dado que hubo una transformación de las Fuerzas Militares y surgieron nuevas amenazas que afectan los intereses nacionales, así como la seguridad y defensa del país.

\section{Importancia de las Fuerzas Militares para la consolidación como Estado}

Las Fuerzas Militares son de vital importancia para poder hablar de estado social de derecho y son parte esencial del desarrollo de todas las formas de estructura democrática, de allí que una de las grandes finalidades del Estado brasileño sea la seguridad (Saint-Pierre, 2009). En este mismo sentido, la propuesta de unificar las operaciones de las tres fuerzas con la creación del Estado Mayor Conjunto de las Fuerzas Armadas no solo constituye una gran innovación, sino que además representa un importante paso en la organización militar que fortalece al Ministerio de Defensa, al Estado y, en consecuencia, a la conducción política de la defensa como factor fundamental en la búsqueda del equilibrio estatal.

Por esta vía el Estado se fortalece gracias a que sus Fuerzas Militares están vinculadas en una organización estructurada por componentes de desarrollo investigativo y profesional, la cual ve como necesidad generar modelos y directrices de seguridad tanto interna, como regional e internacional, todo mezclado de forma racional con el estudio y respeto de los Derechos Humanos como pilar fundamental en la construcción de los modelos de seguridad y defensa. 
Por ejemplo, en el año 2018 las Fuerzas Militares brasileñas tomaron una importancia aún mayor en las actividades de control interno. Para Soares (2018), este fenómeno se debe a la intervención federal en el estado de Río de Janeiro, para lo cual fue designado un general del Ejército, quien realizó de forma eficiente el manejo y control del Secretariado de Seguridad y la Coordinación General de la Seguridad Pública, lo cual evidenció que quedaron bajo tutela militar. Aunque aún es pronto para establecer un balance final de las operaciones y por ahora los resultados han sido poco efectivos, se espera un desarrollo programático eficiente en las relaciones militares y las formas de control de seguridad y defensa.

Si bien se ha desarrollado a ritmos muy distintos en cada uno de los países según las condiciones de organización y los modelos de desarrollo, esta tendencia sentó las bases para una mayor cooperación regional en seguridad y defensa mediante la adopción de mecanismos de concertación y diálogo entre la institucionalidad para soportar las medidas de confianza entre la organización civil y las Fuerzas Militares.

Algo importante en este desarrollo es la profundización del modelo académico militar, que muestra la importancia de unas Fuerzas Militares que apuestan a la ciencia, la tecnología y la investigación para innovar según las necesidades actuales de la sociedad. Además, esto permite que en la esfera política de los vecinos se discutan las posibilidades y las ventajas que conlleva la creación de un espacio de seguridad en el que se beneficien todos en la cooperación del estudio militar.

\section{Contenido normativo en materia de seguridad y defensa nacional}

Para algunos conocedores de la evolución normativa en materia de seguridad y defensa nacional en Brasil, es necesario revisar ciertos aspectos relevantes de esta condición. En el texto "Las generalidades de la política pública de seguridad y defensa del Brasil”, Moncada et al. (2014) establecen que la reorientación de la política pública de seguridad y defensa brasileña hizo trámite desde el cambio de régimen y la instauración de la democracia, que originó, como se mencionó, el paso del control militar a una adecuación para el equilibrio, como lo fue el gobierno civil de Fernando Collor de Mello. 
En estas circunstancias, durante muchos años la estructura se caracterizó por seis componentes: los ministerios del Ejército, la Marina y la Aeronáutica, el Estado Mayor de las Fuerzas Armadas, la Casa Militar de la Presidencia de la República y el Servicio Nacional de Información (Mocada et al., 2014). Cuando vuelve el modelo democrático con la administración Collor de Mello, se suprimió el Servicio Nacional de Información y la estructura quedó reducida solo a cinco instancias. Como lo plantea Acosta (s. f.), esta forma de organización mostraba de forma evidente una supremacía del modelo militar sobre el ejecutivo, situación que atenta contra la estructura democrática que forma parte del equilibrio de los poderes.

Pero el gran cambio en la estructura militar para mejorar las condiciones de seguridad y defensa de la nación brasileńa se dio de forma afortunada en 1996, cuando se incorporó la Política de Defensa Nacional (PDN), en el gobierno del presidente Fernando Enrique Cardoso. Este documento se considera esencial para establecer una política pública de seguridad y defensa desde el contexto militar adecuada a los tiempos de hoy.

Se buscaba entonces un ordenamiento institucional que priorizara el área de seguridad, para lo cual se formuló la PDN como el primer documento sectorial construido para servir de referente institucional en materia de seguridad y defensa. No obstante, los problemas para implementarla fueron evidentes debido, entre otras cosas, a su carácter inédito y particular por el proceso histórico del país, de manera que la PDN se asoció, según Acosta (s. f.), menos a su contenido que a los objetivos necesarios o intereses fundamentales en materia de seguridad.

Su elaboración exclusiva quedó a cargo del Departamento de Políticas y Articulación Institucional y de un círculo selecto de académicos expertos en seguridad y defensa para buscar un equilibrio en el desarrollo del país a través de este mecanismo normativo. Estos expertos dejaron trazada la hoja de ruta sobre el estudio y aplicabilidad de la política de seguridad y defensa de Brasil hasta nuestros días.

Posteriormente, en el año 2005 se aprobó la nueva Política de Defensa Nacional, que intenta solucionar los vacíos y las zonas grises de la política anterior. A continuación, se presentan sus objetivos generales: 
- Definir el empleo y las funciones de las Fuerzas Armadas de Brasil.

- Definir la importancia de la seguridad en las relaciones exteriores de Brasil.

- Propender al perfeccionamiento de la institucionalidad democrática y de transición.

- Instaurar una cultura de defensa en la sociedad brasileńa.

Estos objetivos estaban acordes a las necesidades de Brasil y de la región en materia de seguridad y defensa, pues establecían en un documento concreto las funciones relativas al nuevo orden mundial, definían la importancia de unas Fuerzas Militares que configuraran un trabajo nacional e internacional de cooperación y manejo adecuado de las relaciones exteriores, proponían reforzar la democracia como pilar fundamental para perfeccionar el actuar institucional y extendían como prioridad la defensa de la sociedad en general.

Finalmente, es importante mencionar la tarea que tiene Brasil en el ámbito de la seguridad desde la institucionalidad internacional. Para Carlos Barrachina (2008), los libros blancos de la defensa son un modelo idóneo para reformar o formar al sector seguridad regional de acuerdo con los lineamientos del Consejo de Seguridad Hemisférica de la Organización de Estados Americanos (OeA), por cuanto explican la política y la doctrina de la defensa prevista (analizando la seguridad y el contexto interno), y mencionan la estrategia de reacción frente a los peligros contemplados.

\section{Fundamentos constitucionales de la seguridad y la defensa}

Brasil cuenta con tres instrumentos que se deben considerar para abordar la seguridad y la defensa del país: la Política Nacional de Defensa, la Estrategia Nacional de Defensa y el libro blanco de defensa. Estos instrumentos, al igual que en el caso chileno, tienen un sustento constitucional que dan cabida al desarrollo de cada una de estas normativas. Sobre la estructura y composición del ordenamiento jurídico brasileño se puede establecer que

el concepto estratégico adoptado por Brasil se da en función de una percepción de aguda preocupación en torno a las características y las dinámicas del sistema internacional, aun cuando no se perciben amenazas concretas en el corto y mediano plazo. (Vitelli, 2015, p. 164) 
En este sentido, en el marco constitucional se ha determinado la importancia que tiene el contexto internacional para la seguridad y la defensa de Brasil, relacionadas con la supervivencia del Estado. A partir de esta relevancia, el propio Estado considera de forma constitucional que debe intervenir desde los campos político, militar, económico, psicosocial, científico-tecnológico y medioambiental para lograr su supervivencia.

Esta dinámica de desarrollo desde una orientación constitucional permite cumplir eficazmente las obligaciones estatales con la inversión y visión de un país que se extiende más allá de sus fronteras y que aporta en la construcción de una estabilidad regional, para la cual es fundamental la seguridad y la defensa de los territorios ante las amenazas expuestas para desestabilizar la armonía, el desarrollo y la paz.

\section{Regulación de la seguridad y la defensa nacional en Brasil}

La alineación de los instrumentos jurídicos que regulan la seguridad y la defensa del Estado brasileño constituye uno de los aspectos más relevantes en materia organizacional, lo cual facilita la explicación y el análisis de cada uno de los elementos regulados.

Uno de los puntos de mayor interés del caso brasileño es la manera como la normativa conceptualiza la seguridad y la defensa nacional, pues permite comprender con mayor claridad los diferentes objetivos y características que regula el Estado. En este orden de ideas, la seguridad se define como la condición que le permite al país preservar su soberanía e integridad territorial, promover sus intereses nacionales, libres de presiones y amenazas, y garantizar a los ciudadanos el ejercicio de sus derechos y deberes constitucionales. Por su parte, la defensa nacional es el conjunto de medidas y acciones del Estado, con énfasis en el campo militar, para la defensa del territorio, la soberanía y los intereses nacionales contra amenazas predominantemente externas, potenciales o manifiestas.

El primer componente que es reglamentado por estos instrumentos son los objetivos regulados por la defensa, los cuales están relacionados con los intereses que el propio Estado brasileño ha estipulado de acuerdo con su papel dentro del sistema internacional y las condiciones internas que lo facilitan. 
Otros elementos vinculados a los componentes descritos en los numerales anteriores son las premisas que desarrollan los postulados sobre los objetivos de defensa y los preceptos marco que orientan la seguridad y la defensa de Brasil.

De este modo, los instrumentos que se estudiaron permiten comprobar que para garantizar la seguridad y la defensa nacional es necesario analizar el escenario internacional, de tal manera que se determinen las capacidades con las que cuenta el Estado y se identifiquen las amenazas que afectan la supervivencia.

En relación con la regulación de las capacidades del Estado en el escenario internacional, también cabe señalar que los instrumentos normativos identifican y regulan las amenazas externas del Estado brasileño para justificar el uso de todo su poder militar, el cual se basa, fundamentalmente, en la capacidad de las Fuerzas Armadas y el potencial de los recursos nacionales movilizables.

Asimismo, describen los componentes de la nación que son sujetos de control por parte del Estado, como lo son las aguas jurisdiccionales brasileñas, el territorio y el espacio aéreo, incluidas las zonas continentales y marítimas. También especifican que se debe mantener la seguridad de las líneas de comunicaciones marítimas y las líneas de navegación aérea, especialmente en el Atlántico Sur. Además, resaltan el gran valor que tiene la Amazonia, de manera que consideran esencial llevar a cabo una serie de acciones estratégicas destinadas a fortalecer la presencia militar, la acción efectiva del Estado en el desarrollo sostenible (social, económico y ambiental) y la expansión de la cooperación con los países vecinos con el objetivo de defender las riquezas naturales.

Los instrumentos también establecen diversas formas mediante las cuales la sociedad se hace partícipe de la seguridad y la defensa nacional, como lo es el servicio militar, e involucra a otros sectores, como industriales y académicos, centrados en la producción e innovación científica y tecnológica, quienes deben contribuir a garantizar la satisfacción de las necesidades de los productos de defensa. Así mismo, señalan que los sectores espacial, cibernético y nuclear son estratégicos para la defensa del país, por lo que se deben fortalecer.

Otra de las formas mediante las cuales se realza la alineación estratégica que caracteriza la estructura normativa del Estado brasileño es la creación de 
los postulados de seguridad y defensa que definen la estrategia para el desarrollo de la nación, que se guía por los siguientes principios: (1) movilización de recursos físicos, económicos y humanos para invertir en el potencial productivo del país; (2) capacidad tecnológica autónoma, democratización de las oportunidades educativas y económicas, y (3) oportunidades para ampliar la participación popular en los procesos decisivos de la vida política y económica del país. Entre los componentes que son regulados por estos instrumentos jurídicos se pueden identificar los siguientes:

- Le corresponde al Estado propiciar y garantizar condiciones para que se considere que el país no corre riesgos de agresiones externas, ni tampoco está expuesto a presiones políticas o imposiciones económicas insoportables, y que sea capaz de dedicarse a su propio desarrollo y progreso.

- Brasil ejerce una completa y exclusiva soberanía sobre su territorio, su mar territorial y espacio aéreo sobreyacente y no acepta ninguna forma de intromisión externa en sus decisiones.

- Brasil trabaja en pro de acciones que fortalezcan el acercamiento y la confianza entre los Estados, ya que la valorización y la explotación de esta perspectiva representan un aporte para la prevención de conflictos, capaces de potenciar amenazas a la seguridad nacional.

Por otra parte, la defensa nacional es caracterizada en la PND como "el conjunto de medidas y acciones del Estado, con énfasis en la expresión militar, para la defensa del territorio, de la soberanía y de los intereses contra amenazas preponderantemente externas, potenciales o manifiestas”. Así, en la contextualización del ambiente estratégico el Estado brasileño caracteriza los siguientes escenarios: la unipolaridad ${ }^{6}$, el condominio de $\operatorname{poder}^{7}$ y la multipolaridad.

Igualmente, dentro de este análisis se encuentran los principios generales de uso del instrumento militar que establece el Estado brasileño: la conducción estratégica de las fuerzas, la preparación y el uso del poder militar se realiza de

6 Expresa la preponderancia de un actor hegemónico sobre el sistema internacional.

7 En este escenario la competencia y la coordinación entre dos o pocos polos de poder limitarían la acción de todos los demás actores del sistema. 
acuerdo con la Estructura Militar de Defensa, definida por el Decreto 7276 del 25 de agosto de 2010. Por su parte, define que el componente orgánico de la fuerza está compuesto por (1) el presidente de la República, (2) el ministro de Estado de Defensa, (3) el Consejo Militar de Defensa, (4) los comandantes de las Fuerzas Armadas, (5) el jefe del Estado Mayor Conjunto de las Fuerzas Armadas y (6) los comandantes de los Comandos Operativos.

Además, estos instrumentos normativos mencionan un elemento que adquiere una relevancia particular: la importancia que tiene para el Estado brasileño la participación de la sociedad en la seguridad y la defensa nacional. Consecuentemente, el Estado estipula que la acelerada evolución tecnológica y social ha producido transformaciones sustanciales en los estándares tradicionales de las relaciones políticas y humanas, lo cual ha afectado significativamente las relaciones internacionales y las cualificaciones de seguridad del Estado brasileño y su sistema de defensa. La actuación en este contexto demanda una alta capacidad de análisis crítico para poder entender la coyuntura del presente, anticipar escenarios futuros, identificar informaciones relevantes y traducirlas en una estrategia estatal basada en las posibilidades y capacidades del complejo tecnológico e industrial de defensa y en los recursos militares disponibles. Esas demandas de largo plazo necesitan que haya una relación profunda y estable entre la sociedad y el Estado. La interacción armoniosa entre los órganos de defensa y la sociedad le dan una dinámica mayor a la acción estatal de proveer seguridad y defensa al país. Esa interacción contribuye para el constante perfeccionamiento de la capacidad de identificación y análisis de las demandas de seguridad y defensa nacionales.

La implementación de la PND implica que el Estado tenga la capacidad de incorporar y procesar intereses y demandas ampliamente diversificadas en el ámbito nacional e internacional, compartiendo responsabilidades con la sociedad, tanto en el momento de elegir prioridades, como en el seguimiento y en la evaluación de la acción política. La eficiente gestión de los recursos de defensa del país requiere el equilibrio entre el uso adecuado de los recursos financieros disponibles y las capacidades que se desean de la defensa nacional. La calidad de la implementación de la PND como acción de instrumento gubernamental es un reflejo de la capacidad administrativa del gobierno, así como de las articulaciones entre el Estado y la sociedad. 
Una de las premisas de estos instrumentos es la forma como se comporta el Estado brasileño de cara al sistema internacional. Dado que su posición en el continente le demanda una proyección como potencia, debe desarrollar un componente en política exterior relacionado con la seguridad y la defensa nacional. Reconociendo esta perspectiva, la trayectoria que ha consolidado el Estado brasileño muestra

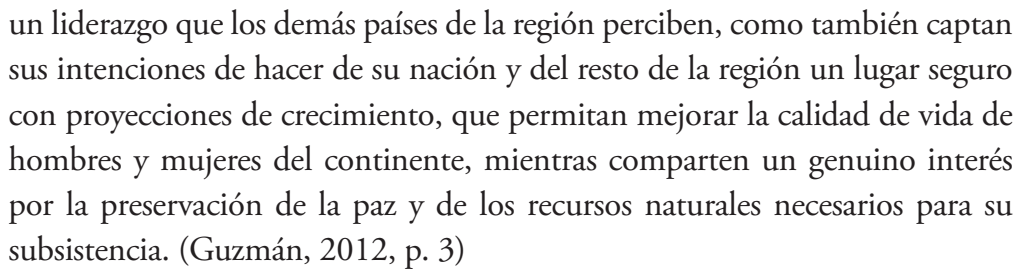

Finalmente, se concluye que cada uno de estos instrumentos evidencia una clara alineación con "prioridades bien definidas en sus planes y directrices. A lo largo de los últimos años, una significativa cantidad de medios militares se han trasladado a puntos clave de la región” (Gomes et al., 2019, p. 181).

\section{Estudio de caso: Argentina}

Si bien Argentina ha desarrollado una política de seguridad y defensa nacional, esta es en realidad un acercamiento a una construcción de un ordenamiento jurídico en la materia, pues le falta una mayor fortaleza en la regulación. En este sentido, en la literatura revisada se encuentra que "el proceso de construcción de una estrategia de seguridad nacional está en marcha en Argentina, en el mediano plazo se verán los resultados" (Rins, 2018, p. 75). Esto no implica que haya un desarrollo de la regulación de la seguridad y la defensa nacional, sino que las bases que se describirán a continuación son el sustento para una proyección que le permita presentar una clara estrategia nacional.

No obstante, el caso de Argentina tiene un gran contenido jurídico en seguridad y defensa que puede ser considerado para el caso colombiano, ya que elaboró esta normatividad luego de un proceso de transición y su formación como nación tiene una interacción considerable con las Fuerzas Militares desde la independencia. 


\section{Proceso de transición}

La transición del control militar a la democracia es una forma de regular el equilibrio y el poder tanto social como militar. El paso al control civil es una transición categórica que tuvo un momento de esplendor en la ciencia política durante la década de 1980 en distintos escenarios mundiales y que ocurrió en el marco de un amplio debate académico sobre las formas de organización desde la seguridad y defensa de los territorios. Como manifiesta Mazzei (2011), estos "procesos tomaron como ejemplo las transiciones históricas de regímenes autoritarios en Europa Meridional, África y América Latina, a las cuales Samuel Huntington denominó 'tercera oleada democratizadora'” (Mazzei, 2011, p. 9).

En el caso específico de Argentina, se evidencia que el país atravesó con éxito el proceso de transición democrática con características particulares que lo diferencian del resto de las transiciones del continente de igual envergadura, sobre las cuales ejerció una profunda influencia. En este escenario se pueden establecer dos contextos importantes, aunque parece haber acuerdo entre los historiadores en que la transición argentina se inició con la restructuración de la política y representación argentina del modelo militar al modelo de orden civil, que algunos autores marcan al comienzo de la apertura en 1980-1981. Puntualmente, se postula el inicio de la transición en marzo de 1980, cuando el general Jorge Videla convocó al diálogo nacional basado en una política democrática en 1983, aunque también hay quienes ubican el comienzo de la liberalización durante el gobierno del general Roberto Viola (1981).

En este proceso las Fuerzas Militares ingresaron a fortalecer las nuevas dinámicas de desarrollo y una nueva estructuración permitió reorganizar el aparato militar con el propósito de buscar la estabilización social. Asimismo, las Fuerzas Militares tuvieron la misión de capacitar sus fuerzas en el respeto de los Derechos Humanos, pensando en buscar la seguridad y la defensa nacional y el compromiso de articulación regional.

\section{Importancia de las Fuerzas Militares para la consolidación como Estado}

En cuanto a la importancia de las Fuerzas Militares en los nuevos procesos democráticos, se puede considerar que su participación es trascendental en la organización y cumplimiento del estado social de derecho y en los compro- 
misos de índole internacional que asumen los Estados. Específicamente, las transiciones compuestas en el desarrollo de las políticas públicas en Argentina han permitido democratizar los componentes de la organización militar y su importancia en el aparato estatal, así como institucionalizar la participación en el proceso de armonía y equilibrio social. Como se evidencia en este y en los otros casos estudiados, los Estados latinoamericanos tienen problemáticas comunes para consolidar regímenes cuya legitimidad se fundaf mente en la participación democrática, la justicia y el respeto a los Derechos Humanos, además de la colaboración armónica regional en materia de defensa y seguridad. En Argentina, en este proceso ha sido crucial la colaboración de las Fuerzas Armadas, un actor que en el pasado fue tildado por sus actuaciones políticas, pero que hoy se reivindica como un organismo democrático y con una conciencia del deber sobre las premisas internacionales y constitucionales del respeto a los Derechos Humanos como base fundamental de la seguridad interna y externa.

El proceso argentino evidencia la capacidad que tienen sus Fuerzas Militares para adaptarse a las necesidades de hoy y aprender las lecciones del pasado. En este sentido, cabe señalar que la transición democrática argentina es excepcional en el contexto latinoamericano debido a las actuaciones, el juzgamiento y la condena de importantes responsables de violaciones a los Derechos Humanos. Esa singularidad de la transición argentina es valorada por Acuña y Smulovitz (2007), quienes resaltan el importante proceso de reconstrucción democrática y la participación activa de las Fuerzas Militares en la era constitucional.

Los retos actuales le imponen a la nación argentina fomentar la cooperación regional para afrontar los retos en el debate político y en la discusión académica sobre el problema de la seguridad y la defensa, la obligación constitucional que tiene como Estado moderno de regular la manera como trata a los responsables del terrorismo de Estado y, simultáneamente, asegurar la transición y consolidación democrática dentro de un proceso coordinado entre la institucionalidad del Estado.

\section{Contenido normativo en materia de seguridad y defensa nacional}

En este apartado se describe cada una de las características que integran el contenido normativo en materia de seguridad y defensa en el caso argentino. 
Como se ha hecho hasta ahora, se hace referencia a los elementos que puedan ser considerados como referentes para el contenido jurídico del Estado colombiano, en aspectos como amenazas, capacidades, competencias, entre muchos otros.

\section{Fundamentos constitucionales de la seguridad y la defensa nacional}

La Constitución argentina esboza las características de la seguridad y la defensa de la República, comenzando por considerar a la defensa nacional como una obligación esencial e indelegable del Estado, en la cual deben coincidir todos los esfuerzos necesarios para preservar los intereses vitales de la nación. Asimismo, el inciso 12 del artículo 99 de la Constitución nacional determina que la Presidencia es la comandante en jefe de todas las Fuerzas Armadas, por lo cual le corresponde diseñar su política y conducir su gobierno. Además, se reitera, como se ha observado en los otros países, la importancia que tiene identificar no solo la seguridad y la defensa como un servicio a cargo del Estado, sino también cada uno de los intereses y bienes que deben ser protegidos de las amenazas que los puedan afectar.

Otro de los aspectos que reglamenta la Constitución consiste en que el Estado es el responsable de ejercer la plena conducción civil de la política de defensa nacional. Con este propósito, debe impartir directivas políticas claras que establezcan, de manera rigurosa, los criterios y lineamientos a los que deberá ajustarse la política de defensa, la política militar y, consecuentemente, la organización y el funcionamiento del instrumento militar de la nación. Cabe agregar que estas directivas describen los principales lineamientos del nivel estratégico nacional, en particular la concepción y el posicionamiento estratégico que seguirán orientando y conduciendo la defensa nacional.

\section{Regulación de la seguridad y la defensa nacional en Argentina}

A pesar de que el país no tiene un libro blanco de defensa, el análisis realizado al caso argentino evidenció que existen unas bases constitucionales sobre la seguridad y la defensa nacional, junto con una variedad de leyes que integran los instrumentos jurídicos sobre la materia, dentro de los cuales se encuentra la regulación de la política sectorial.

Asimismo, se han desarrollado otras normas que establecen aspectos adicionales a la seguridad y la defensa nacional, como las leyes de Defensa 
Nacional N. ${ }^{\circ} 23554$, de Seguridad Interior N. 24059, de Reestructuración de las Fuerzas Armadas N. 24948 y de Inteligencia Nacional N. ${ }^{\circ} 25520$, las cuales definen los lineamientos, las prioridades y las restricciones en materia de defensa nacional.

Entre las diversas normas que regulan la materia, Argentina cuenta con el artículo 2. ${ }^{\circ}$ de la Ley 23554, reglamentado por el artículo 1. ${ }^{\circ}$ del Decreto 727 de 2006, según el cual la misión principal del instrumento militar del Sistema de Defensa Nacional es repeler y conjurar agresiones militares estatales externas contra los intereses vitales de la República argentina, siendo esta finalidad uno de los componentes por los cuales se diferencia la seguridad y la defensa.

Por ello, el artículo 4. ${ }^{\circ}$ de la Ley 23554 y los artículos 31 y 32 de la Ley 24059 hacen una clara distinción jurisdiccional, orgánica y funcional entre la defensa nacional y la seguridad interior para diferenciar la naturaleza de ambas problemáticas y las responsabilidades hacia el interior del Estado nacional. En concordancia con los criterios establecidos por el artículo 3. ${ }^{\circ}$ del Decreto 727 de 2006, el Sistema de Defensa Nacional no podrá planificar ni desarrollar actividades relacionadas con la seguridad interior.

Como parte de los instrumentos que desarrollan los temas de seguridad y la defensa nacional en Argentina, el Ciclo de Planeamiento de la Defensa Nacional —aprobado por el Decreto 1729 de 2007- estableció el procedimiento para identificar y determinar las instrucciones rectoras de la Política de Defensa Nacional, de su derivada Política Militar, así como de todos los factores de las capacidades del instrumento militar compuestas por el material, la información, los recursos humanos, la infraestructura, la logística, el adiestramiento, la doctrina y la organización.

Particularmente, la Política de Defensa de la Nación se fundamenta en el inequívoco respeto y promoción de la democracia, el estado de derecho, los Derechos Humanos, la autodeterminación de los pueblos, la protección de los recursos estratégicos, la vocación por la paz y la justicia, el apego al derecho internacional y al sistema multilateral como instrumentos centrales para regular las relaciones interestatales y resolver las controversias entre los Estados. Asimismo, este instrumento normativo tiene la firme convicción de que la cooperación interestatal tiene una importancia irreemplazable como 
medio de construcción y consolidación de la paz, la defensa regional y la seguridad internacional. La Política de Defensa de la Nación encuentra en el concepto de "legítima defensa" el criterio esencial y ordenador sobre el cual se estructura todo el Sistema de Defensa del Estado argentino, que rechaza las políticas estratégicas de agresión en cuanto se encuentran por fuera del marco jurídico internacional vigente.

\section{Lecciones aprendidas de Centroamérica}

Los casos de diversos países de Centroamérica tienen un importante valor para el desarrollo de esta investigación, dado que sus procesos de transición han tenido similitudes con el caso colombiano. Al igual que Colombia, algunos países de la región han pasado por procesos de implementación de la paz después de vivir largos y complejos conflictos civiles, además de que los graves problemas de seguridad que enfrentan actualmente constituyen valiosas lecciones aprendidas. Para esto, a continuación se hace un acercamiento a este tipo de conflictos con el fin de dilucidar con mayor claridad las lecciones que dejan estas experiencias.

Análisis sobre los casos de posconflicto de El Salvador, Guatemala y Nicaragua

Los procesos de paz de El Salvador, Guatemala y Nicaragua de los años noventa fueron la salida a prolongados e intensos conflictos armados que azotaron la región centroamericana. Los distintos actores consideraron este momento como "el punto de partida para el establecimiento de un proyecto estatal que superará las causas del conflicto y que llevará a la población a una convivencia sana en el posconflicto" (Garzón, 2014, p. 120). Sin embargo, desafortunadamente "no terminaron con las causas estructurales que los determinaron; por lo tanto, la violencia mutó hacia nuevas características” (Garzón, 2014, p. 145).

Hay tres características que se pueden considerar similares en estos casos de Centroamérica. En primer lugar, se desarrollaron como efecto o reflejo de las dinámicas que generó la Guerra Fría, dado que en cada uno de ellos la ideología del comunismo y del capitalismo fue el sustento o la justificación de los actores que participaron en estos procesos. Así, en el marco de esta confrontación ideológica se evidencia que estas naciones han tratado de forma superfi- 
cial los problemas estructurales de sus sociedades, como la desigualdad social, que en el fondo son el origen de los conflictos. Desde luego, para este estudio se trata de una característica importante que debe ser considerada cuando se analice la forma como se resolvieron estos conflictos $y$, por ende, la continuidad de sus problemas de violencia.

En segundo lugar y consecuente con lo anterior, la terminación de estos conflictos se originó en el ocaso de la Guerra Fría, cuando los Estados Unidos usaron los Derechos Humanos como forma de cohesión internacional y tuvo lugar la caída de la Unión de Repúblicas Socialistas Soviéticas (URSS), pues ambos factores debilitaron la fuerza de cada uno de los actores en estos conflictos y los llevó a la negociación. Por último, la tercera característica en común es que estas naciones tuvieron dificultades para proteger los Derechos Humanos, lograr justicia de los crímenes cometidos y materializar la transición debido a la falta de cumplimiento de lo pactado. Estas circunstancias serán retomadas para analizar la continuidad de la violencia y los problemas de seguridad en estas naciones.

Esta descripción se fundamenta en el análisis que hace Moreno (2017) sobre el caso de El Salvador. De acuerdo con el autor, el conflicto en este país estuvo enmarcado por el contexto de la Guerra Fría y contó con múltiples actores: fuerzas paramilitares, el Estado y grupos insurgentes, quienes se vieron en la necesidad de llegar a los acuerdos de paz ante la caída del Muro de Berlín y las dinámicas del mundo bipolar. Sin embargo, este proceso de transición enfrentó varias problemáticas: lograr juicios que reconocieran los responsables de las graves violaciones de Derechos Humanos y hacer una verdadera reparación a las víctimas, además de que no se consideró una solución a los conflictos o causas estructurales de la violencia.

Para el caso de Guatemala, se trae a colación la investigación de los profesores Ball et al. (1999), quienes hacen una precisa descripción del conflicto interno en Guatemala. Los autores señalan que se trata de un conflicto de 36 años en el que se presentaron diferentes niveles de violencia, los cuales se pueden diferenciar por décadas, cada una caracterizada por la intensidad del conflicto. Durante este periodo, el conflicto pasó de los centros urbanos al campo y a la selva, y luego retornó a los centros urbanos y nuevamente al 
sector rural. Asimismo, participaron múltiples actores, entre fuerzas paramilitares, insurgencia y el Estado, que por las mismas circunstancias del fin de la Guerra Fría se vieron abocados a lograr una negociación. No obstante, la falta de juicios sobre los crímenes y de protección a los Derechos Humanos prolongaron los problemas de seguridad y violencia.

En el caso de Nicaragua, Farré (1991) afirma que a pesar de ser uno de los casos en que la insurgencia logró llegar al poder durante el desarrollo de la Guerra Fría, el conflicto solo terminó luego de las elecciones de 1990, cuando la insurgencia perdió el poder de forma democrática. De acuerdo con el autor, en este proceso hubo periodos de dictadura militar, un gobierno de insurgencia y la existencia de guerrillas de derecha que eran sustentadas por los Estados Unidos en contra del gobierno. En Nicaragua también se reiteran las características que se han mencionado en los otros casos: múltiples actores, la existencia del conflicto como reflejo de las dinámicas de la Guerra Fría y su culminación a causa del propio declive del mundo bipolar, así como problemas para tratar temas como la justicia, la protección de los Derechos Humanos y la reparación a las víctimas, lo cual ha facilitado que los problemas en seguridad continúen en esta nación.

Estos ejemplos demuestran que "el desafío principal no es conseguir la firma de la paz, sino la redefinición del Estado como tal y su reconstrucción bajo nuevos principios y valores que permitan la recuperación de la economía, la inclusión social y la disminución de la desigualdad” (Garzón, 2014, p. 145). En consecuencia, los desafíos para los gobiernos en posconflicto son amplios y trascendentales. El adecuado manejo de los excedentes de armas y municiones de los conflictos y la lucha frontal y determinada contra el crimen organizado son elementos clave para asegurar un proceso de posconflicto real y que atienda las causas estructurales del conflicto (Garzón, 2014).

Los procesos de paz en Guatemala y El Salvador demostraron que a través de la negociación pacífica entre el gobierno y el grupo armado sí es posible llegar a un acuerdo de paz que devuelva esos derechos fundamentales a la sociedad y que permita a ambas partes negociadoras satisfacer sus intereses, pero teniendo en cuenta mecanismos de justicia. Finalmente, y no menos importante, muestran el papel que tiene el apoyo de países o entes externos 
como la Organización de Naciones Unidas, que contribuyen a brindar seguridad en los escenarios de posconflicto (Gutiérrez, 2017).

Finalmente, en el caso de Centroamérica, la información disponible parece sugerir que se quiere focalizar el gasto de defensa en las particularidades de cada país. Particularmente, el Anuario de estadisticas de finanzas públicas del Fondo Monetario Internacional (FMI, 200I) refleja que organismos internacionales como la ONU han tenido un gasto en seguridad y defensa muy controlado en la región, especialmente el Consejo de Seguridad, donde se aprueba para ciertas regiones las resoluciones sobre la disminución del presupuesto militar en función de una nueva etapa de organización más regional en defensa y seguridad coordinada.

\section{Lecciones aprendidas sobre los casos de posconflicto de los paises de Centroamérica}

En este apartado se presentan los componentes normativos que regulan la seguridad y defensa en El Salvador, Guatemala y Nicaragua y que se deben tener en cuenta para construir en Colombia una ley de seguridad y defensa nacional. Asimismo, de cara a determinar las lecciones aprendidas de estos procesos, es necesario tener presente que estas naciones tienen actualmente nuevas amenazas o una convergencia de amenazas que afectan su seguridad y defensa.

En el caso de El Salvador, la Política de Defensa, como política pública, es un conjunto de directrices que tienden a la preservación del Estado e interpretan los intereses nacionales plasmados en la Constitución Política de la República en el contexto de la seguridad nacional. Así, define cursos de acción para prevenir y/o enfrentar las amenazas con base en la evaluación y priorización de los objetivos. La Política de Defensa constituye parte de la política nacional que dicta o determina los objetivos de la defensa nacional, los cuales ordenan la preservación de los intereses y los objetivos nacionales plasmados en la Constitución Política de la República en el contexto de la seguridad democrática.

Por su parte, la Política de Defensa Nacional de Guatemala se define a partir de los objetivos nacionales y se desarrolla mediante un proceso participa- 
tivo de los sectores de gobierno y de la sociedad. La Política de Defensa refiere a aquellos principios y normas de carácter general que, originados en los máximos niveles de conducción, cuentan con el consenso de los factores sociales y políticos, y tienen por objeto preservar los intereses vitales del país. Esta política es un documento de conocimiento y acción pública, coherente en lo conceptual, lo metodológico y lo estratégico. La participación en operaciones de paz en el exterior es una parte importante de esta Política de Defensa, en la medida en que contribuya a la consecución de los intereses vitales y estratégicos del Estado guatemalteco para lograr el reconocimiento internacional de la participación del Ejército de Guatemala en operaciones de apoyo a países amigos.

La defensa nacional es un ámbito político por excelencia que compromete en su desarrollo a toda la nación. La modernización de las instituciones de la defensa nacional constituye uno de los pilares fundamentales en los cuales se apoya la Política de Defensa. El proceso de transformación y modernización del Ejército de Guatemala es otro de los pilares de la política, de acuerdo con los parámetros fijados y los desafíos actuales que inciden en dicho proceso, a fin de obtener los recursos necesarios para mantener unas Fuerzas Armadas altamente móviles y profesionales.

La Política de Defensa está sujeta a dos condicionantes. Por una parte, debe ser permanente, para que no sufra modificaciones por cambios en el gobierno que impliquen decisiones de alto costo. Por otra parte, debe ser dinámica y flexible, para que pueda adaptarse a los cambios nacionales e internacionales, lo que le permitirá responder a los desafíos que pueden generar transformaciones en el corto y mediano plazo.

El estudio de estos casos también evidencia que uno de los aspectos que más inciden en la continuidad de la violencia en Centroamérica es el incumplimiento de los acuerdos, es decir, que no se ha logrado solucionar las causas estructurales del conflicto. Como esta falta de cumplimiento prolonga las amenazas que potencian el desarrollo de los conflictos y la violencia, una lección aprendida para Colombia y todo su aparato institucional es que debe materializar los acuerdos, de tal manera que logre no solo la administración de justicia — ya sea dentro del marco de la transición—, sino también hacer reformas estructurales que solucionen, entre otros, los problemas sociales. 


\section{Discusión}

Tabla 1. Principales características de los casos estudiados

\begin{tabular}{|c|c|c|c|c|}
\hline País & $\begin{array}{c}\text { Proceso } \\
\text { de transición }\end{array}$ & $\begin{array}{l}\text { Importancia de las } \\
\text { Fuerzas Militares } \\
\text { para el país }\end{array}$ & $\begin{array}{l}\text { Contenido } \\
\text { normativo }\end{array}$ & $\begin{array}{l}\text { Componentes que } \\
\text { se deben sustraer }\end{array}$ \\
\hline Chile & $\begin{array}{l}\text { A diferencia del } \\
\text { caso colombiano, se } \\
\text { trata de un proceso } \\
\text { hacia la democracia } \\
\text { después de un } \\
\text { periodo de dicta- } \\
\text { dura. Igualmente, } \\
\text { demandó una } \\
\text { transformación } \\
\text { institucional para } \\
\text { lograr que la transi- } \\
\text { ción se consolidara. }\end{array}$ & $\begin{array}{l}\text { Se evidencia que } \\
\text { es necesario contar } \\
\text { con la participa- } \\
\text { ción de las Fuerzas } \\
\text { Militares, en razón } \\
\text { a que siempre han } \\
\text { estado en la conso- } \\
\text { lidación nacional. } \\
\text { Asimismo, se } \\
\text { comprueba que } \\
\text { dentro de sus } \\
\text { reformas en materia } \\
\text { de seguridad y } \\
\text { defensa mantiene } \\
\text { un reconocimiento } \\
\text { a las Fuerzas } \\
\text { Militares que es } \\
\text { aceptable social- } \\
\text { mente, pero que } \\
\text { también tiene } \\
\text { un sustento en la } \\
\text { propia construcción } \\
\text { como nación. }\end{array}$ & $\begin{array}{l}\text { Este resulta ser uno } \\
\text { de los elementos } \\
\text { que tienen una } \\
\text { gran relevancia } \\
\text { para este capítulo, } \\
\text { no obstante, no } \\
\text { se puede perder } \\
\text { de vista que para } \\
\text { aplicarlo en el caso } \\
\text { colombiano es } \\
\text { indispensable el } \\
\text { cumplimiento de } \\
\text { las otras variables, } \\
\text { que determinan } \\
\text { su similitud con } \\
\text { el país. } \\
\text { En el caso chileno } \\
\text { se logró evidenciar } \\
\text { los elementos } \\
\text { constitucionales } \\
\text { relevantes que } \\
\text { integran los inte- } \\
\text { reses nacionales y } \\
\text { las características } \\
\text { normativas. }\end{array}$ & $\begin{array}{l}\text { Definición de } \\
\text { seguridad y defensa } \\
\text { para el país. } \\
\text { Identificación de las } \\
\text { amenazas. } \\
\text { Necesidad de la } \\
\text { integración con la } \\
\text { política exterior del } \\
\text { país. } \\
\text { Medios y capaci- } \\
\text { dades del Estado } \\
\text { para seguridad y } \\
\text { defensa. } \\
\text { Control territorial. } \\
\text { Todos los campos } \\
\text { de acción del Estado } \\
\text { en favor de la segu- } \\
\text { ridad y la defensa } \\
\text { nacional. }\end{array}$ \\
\hline Brasil & $\begin{array}{l}\text { Se presenta un } \\
\text { proceso de transi- } \\
\text { ción hacia la demo- } \\
\text { cracia, pero que } \\
\text { sigue demandando } \\
\text { una transformación } \\
\text { institucional para } \\
\text { consolidarlo. }\end{array}$ & $\begin{array}{l}\text { Es de gran impor- } \\
\text { tancia esta circuns- } \\
\text { tancia porque } \\
\text { demuestra que las } \\
\text { reformas institucio- } \\
\text { nales desarrolladas } \\
\text { reconocen a las } \\
\text { Fuerzas Militares } \\
\text { y que se deben } \\
\text { considerar en las } \\
\text { reformas correspon- } \\
\text { dientes. }\end{array}$ & $\begin{array}{l}\text { Se evidencia } \\
\text { que existe un } \\
\text { compendio dentro } \\
\text { de sus libros } \\
\text { blancos de defensa } \\
\text { en materia de segu- } \\
\text { ridad y defensa. }\end{array}$ & $\begin{array}{l}\text { Definición de segu- } \\
\text { ridad y defensa. } \\
\text { Necesidad de la } \\
\text { integración con la } \\
\text { política exterior del } \\
\text { país. } \\
\text { Fomento de la } \\
\text { innovación desde la } \\
\text { academia en favor } \\
\text { de la seguridad y la } \\
\text { defensa nacional. } \\
\text { Descripción de } \\
\text { las capacidades y } \\
\text { medios del Estado. } \\
\text { Análisis profundo } \\
\text { de las amenazas } \\
\text { externas. }\end{array}$ \\
\hline
\end{tabular}

Continúa tabla... 


\begin{tabular}{|c|c|c|c|c|}
\hline País & $\begin{array}{l}\text { Proceso } \\
\text { de transición }\end{array}$ & $\begin{array}{c}\text { Importancia de las } \\
\text { Fuerzas Militares } \\
\text { para el país }\end{array}$ & $\begin{array}{l}\text { Contenido } \\
\text { normativo }\end{array}$ & $\begin{array}{l}\text { Componentes que } \\
\text { se deben sustraer }\end{array}$ \\
\hline Argentina & $\begin{array}{l}\text { Se trata de una } \\
\text { transición hacia la } \\
\text { democracia luego } \\
\text { de un régimen tota- } \\
\text { litario, que igual- } \\
\text { mente demanda } \\
\text { una transformación } \\
\text { del Estado para } \\
\text { alcanzar dicho } \\
\text { objetivo. }\end{array}$ & $\begin{array}{l}\text { La importancia } \\
\text { de las Fuerzas } \\
\text { Militares resulta } \\
\text { relevante porque } \\
\text { las reformas enca- } \\
\text { minadas o desarro- } \\
\text { lladas para alcanzar } \\
\text { la transición consi- } \\
\text { deran este sustento } \\
\text { histórico, en simi- } \\
\text { litud con el caso } \\
\text { colombiano. }\end{array}$ & $\begin{array}{l}\text { A pesar de que } \\
\text { no tiene un libro } \\
\text { blanco de defensa, } \\
\text { tiene leyes que en } \\
\text { su conjunto regulan } \\
\text { los temas relacio- } \\
\text { nados con la segu- } \\
\text { ridad y la defensa } \\
\text { nacional. }\end{array}$ & $\begin{array}{l}\text { Definición de segu- } \\
\text { ridad y defensa. } \\
\text { Identificación de las } \\
\text { amenazas. } \\
\text { Capacidad y medios } \\
\text { del Estado. } \\
\text { Diplomacia para la } \\
\text { defensa. } \\
\text { Innovación desde } \\
\text { la academia para } \\
\text { la seguridad y la } \\
\text { defensa. } \\
\text { Diferenciación clara } \\
\text { de funciones entre } \\
\text { las autoridades que } \\
\text { integran la fuerza } \\
\text { pública. }\end{array}$ \\
\hline $\begin{array}{l}\text { Países de } \\
\text { Centroamérica }\end{array}$ & $\begin{array}{l}\text { Son los más simi- } \\
\text { lares al colombiano, } \\
\text { pues se trata de } \\
\text { procesos de transi- } \\
\text { ción ante conflictos } \\
\text { internos. En este } \\
\text { sentido, es posible } \\
\text { aprender tanto de } \\
\text { las medidas que } \\
\text { tomaron, como de } \\
\text { las que repercu- } \\
\text { tieron en empeorar } \\
\text { las condiciones de } \\
\text { seguridad. }\end{array}$ & $\begin{array}{l}\text { La mayoría de } \\
\text { estos países ha } \\
\text { tenido una marcada } \\
\text { participación } \\
\text { de las Fuerzas } \\
\text { Militares, que han } \\
\text { determinado su } \\
\text { importancia en las } \\
\text { transformaciones } \\
\text { institucionales de } \\
\text { cara a la transición. }\end{array}$ & $\begin{array}{l}\text { Se evidencia la falta } \\
\text { de una implemen- } \\
\text { tación adecuada } \\
\text { de los acuerdos } \\
\text { que permitieron la } \\
\text { transición. }\end{array}$ & $\begin{array}{l}\text { La falta de trans- } \\
\text { formación institu- } \\
\text { cional. } \\
\text { Falta de control } \\
\text { territorial por el } \\
\text { Estado. } \\
\text { Falta de partici- } \\
\text { pación de todos } \\
\text { los actores de los } \\
\text { conflictos. }\end{array}$ \\
\hline
\end{tabular}

Fuente: elaboración propia con base en la información utilizada para el análisis de cada una de las variables en los casos estudiados.

Para comenzar con la discusión, en la tabla 1 se analizan los principales componentes de los casos estudiados, de tal manera que se pueda identificar cuáles son pertinentes para definir una ley de seguridad y defensa nacional.

Con todo lo descrito anteriormente y como se mencionó al principio del capítulo, se debe considerar el derecho como el ordenamiento institucional con fuerza coactiva encargado de regular los efectos externos de las relaciones que se presentan en una sociedad. En este sentido y aplicando esta definición a la seguridad, se puede establecer que el derecho regulará los efectos que generen 
las diferentes conductas realizadas con el fin de lograr el mencionado estado o condición de estar libre de amenazas.

En el caso colombiano, la regulación normativa sobre seguridad y defensa debe establecer los siguientes elementos: (1) los intereses que el Estado debe proteger, lo cual varía en razón al enfoque que se estipule sobre seguridad, que no solo se trata de la protección de los derechos de las personas, sino también de la supervivencia del Estado; (2) el tipo de medios y recursos con los cuales cuenta el Estado para proteger sus intereses; (3) la identificación de las amenazas y los factores de inestabilidad que son considerados por cada nación; (4) la forma mediante la cual se puede hacer uso de los recursos y medios con los cuales cuenta cada Estado, y (5) la descripción de los elementos que deben ser considerados como infraestructura crítica para la subsistencia del Estado, tomando en consideración cada uno de los preceptos que fueron tratados en el capítulo.

Del análisis realizado hasta el momento se pueden identificar varios elementos que se deben tener en cuenta para desarrollar una ley de seguridad y defensa en Colombia. En primer lugar, es necesario evidenciar la relación que tiene la ley de seguridad y defensa con los sustentos internacionales y constitucionales, lo cual se materializa reconociendo explícitamente en la norma los intereses y bienes que son definidos por estos niveles internacionales y constitucionales. En segundo lugar, se debe regular cada una de las capacidades que tiene el Estado (medios y modos) para proteger dichos intereses de las amenazas que los lleguen a afectar. En consecuencia, resulta oportuno definir una ley de seguridad y defensa para que estos instrumentos normativos perduren a pesar de los diferentes gobiernos, sobre todo si se considera que es por medio de esta norma jurídica que se puede consolidar y desarrollar una política pública debidamente estructurada.

El primer componente que debe tener esta normatividad es una descripción de los fundamentos constitucionales que estabulen la seguridad y defensa como un deber del Estado y relacionado con sus fines, teniendo en consideración que son este tipos de normas las que dan fundamento a la existencia propia del Estado, según el fundamento teórico del contractualismo. De esta manera se incorporan los mencionados intereses nacionales, pues la Constitución en 
los Estados hace referencia al poder constituyente que lo genera, por lo cual la ley de seguridad y defensa que busca protegerlos no puede desconocer los lineamientos que la Constitución ha configurado respecto de lo que se busca proteger y los medios por los cuales se puede lograr.

Otro de los componentes que debe integrar este tipo de normas consiste en la aclaración de los fines por los cuales se guía la seguridad y la defensa, con el objetivo de establecer un control a las facultades que tiene el Estado al momento de implementar la fuerza, capacidades y demás medios de cara a la seguridad y defensa, pues se estipula con claridad en qué momentos deben implementarse. Como se ha mencionado, estos fines deben estar relacionados con los perceptos constitucionales que garantizan su relación con la nación.

Cabe resaltar que la descripción de estos fines permite dar la claridad que necesitan las instituciones estatales, principalmente la fuerza pública, para generar estrategias adecuadas que les permitan proteger y alcanzar estos fines. No se puede olvidar que para ello es imprescindible contar con el apoyo de las demás instituciones estatales, pues las características de las amenazas demandan que todos los involucrados participen. A manera de ejemplo, si se estipula como uno de los fines del Estado brindar orden público a las personas, entonces no es suficiente con señalar que esta será una responsabilidad de la Policía, sino que además es indispensable acompañar este mandato con una política criminal que permita una acción colaborativa entre la Fiscalía y la judicatura para definir sanciones y penas que en verdad mitiguen los índices de criminalidad como parte del orden público. Este ejemplo demuestra la importancia de establecer fines claros para permitir la participación de todos los actores involucrados en la seguridad y la defensa de la nación.

En el caso colombiano, la ley de seguridad y defensa debe incorporar un componente territorial que considere los factores particulares que se presentan en las diferentes regiones del país. Asimismo, es necesario que reconozca las características específicas de cada zona y regule los medios que el Estado debe emplear para fortalecer sus potencias y mitigar las amenazas que se arraigan en los territorios. Se trata, sin duda, de uno de los puntos que permiten dar mayor claridad a este tipo de instrumentos y, consecuentemente, a los demás elementos que integra la ley, por lo cual esta debe hacer un análisis riguroso 
no solamente del campo local, sino también del regional e internacional para que identifique los diferentes fenómenos y factores que se pueden convertir en amenazas u oportunidades para el Estado.

Otro de los elementos que esta ley debe desarrollar es la planificación de la defensa, de modo que determine con claridad la (1) conducción, desarrollo y empleo de los medios de la defensa, (2) las modalidades de empleo de los medios de la defensa y (3) los aspectos generales del gasto y la inversión en defensa. Además, una ley de seguridad y defensa también debe definir, precisamente, la relación entre la seguridad y la defensa, junto con la política exterior, teniendo en cuenta que esta última constituye una de las formas mediante las cuales el Estado puede alcanzar sus intereses en materia de seguridad y defensa.

Al considerarse como un nuevo factor en la geopolítica, pero también en el desarrollo de las naciones, la ley de seguridad y defensa también debe abordar los aspectos económicos, de tal manera que brinde seguridad al desarrollo económico del país y con esto contribuya a los fines del Estado. La ley debe distinguir con nitidez entre la seguridad y la defensa nacional, de tal manera que las instituciones hagan un uso adecuado de los medios con los que cuenta el Estado y de las formas mediante las cuales pueden ejecutar dichas capacidades para lograr la protección de la nación y alcanzar sus diferentes fines.

Finalmente, se concluye que el análisis comparativo de los instrumentos normativos de varios países de la región permitió identificar los principales elementos para definir una ley de seguridad y defensa en Colombia en el marco de la implementación de los acuerdos de paz. Esta extrapolación se fundamenta en la similitud que tienen los casos estudiados con Colombia, esto es, también pasaron por procesos de transición — tanto de conflictos no internacionales como de dictaduras_- y cuentan en la actualidad con una regulación en materia de seguridad y defensa, lo cual permite, precisamente, proyectar una ley de seguridad y defensa que estructure el accionar del Estado colombiano de cara a la protección de sus intereses y sus bienes nacionales, en el término y las condiciones que se han presentados en este capítulo. 


\section{Conflicto de intereses}

Los autores no reportan ningún conflicto de interés en la realización de la presente obra.

\section{Agradecimientos}

Los autores agradecen a cada uno de los actores que permitieron y facilitaron el desarrollo de la obra, tanto de la Universidad Militar Nueva Granada como al Sello Editorial de la Escuela Militar de Cadetes "General José María Córdova".

\section{Financiación}

Este trabajo fue apoyado por el proyecto de investigación INV-EES 2975 titulado "El panorama del post conflicto en Colombia: Un acercamiento desde la gobernanza y la reforma del sector seguridad", financiado en su totalidad por la Universidad Militar Nueva Granada.

\section{Referencias}

Acosta, C. (s. f.). La politica de defensa brasileña: Diagnósticos, propuestas y perspectivas para la cooperación regional. Programa de Cooperación en Seguridad Regional.

Acuña, C., \& Smulovitz, C. (2007). Militares en la transición argentina: Del gobierno a la subordinación constitucional. En Historizar el pasado vivo en América Latina (pp. 3-94). http://ijdh.unla.edu.ar/advf/documentos/2018/03/5aba57caaf2a2.pdf

Ball, P. D., Kobrak, P., Spirer, H. F., \& Castillo, R. M. (1999). Violencia institucional en Guatemala, 1960 a 1996: Una reflexión cuantitativa. American Association for the Advancement of Science.

Barrachina, C. (2008). Programa interno de medidas de confianza mutua.

Díaz, J. (2003). Fuerzas Armadas y sociedad: El caso de Chile. Cuadernos de Estrategia, 123, $87-125$.

Eisenhardt, K. M. (1989). Building theories from case study research. Academy of Management Review, 14(4), 532-550.

Farré, J. A. (1991). Dos guerras en Nicaragua: 1978-1988. Espacio, Tiempo y Forma. Serie V, Historia Contemporánea, 4. https://doi.org/10.5944/etfv.4.1991.2741 
Freer, J. B., \& Wehner, L. E. (2018). Los desafíos de seguridad para Chile: definiciones para escenarios múltiples. RESI: Revista de Estudios en Seguridad Internacional, 4(1), 19-35.

Garzón, C. A. D. (2014). Violencia luego de la paz: Escenarios de posconflicto en Centroamérica. Revista Republicana, 17, 119-148. http://revista.urepublicana.edu.co/wp-content/ uploads/2015/02/Violencia-luego-de-la-paz-escenarios-de-posconflicto-en-Centro-.pdf

Gomes, F. Agudelo, F. J. Bernal, R. Casallas, N. J., \& Casagrande, F. (2019). Modelo brasileńo de seguridad y defensa para la región amazónica - un referente para Colombia. En A. Montero (ed.), Amazonia. Poder y estrategia. (pp. 157-182). Escuela Superior de Guerra.

Guzmán, V. (2012). Estatus militar de Brasil y su estrategia de seguridad y defensa. Academia de Estudios Políticos y Estratégicos.

Mazzei, D. (2011). Reflexiones sobre la transición democrática argentina. Pol His, 4(7), 8-15.

Moncada, L. A. M., Herrera, Á., \& Pérez, L. A. (2014). Análisis comparado de las políticas públicas de defensa de México y Brasil. Retos de una nueva contrainsurgencia. Papel Político, 19(2), 631-655.

Moreno, J. D. (2017). Paz, memoria y verdad en El Salvador: Experiencias y lecciones para la Colombia del posacuerdo. Análisis Político, 30(90), 175-193.

Rins, J. M. (2018). Argentina: Estrategia de Seguridad Nacional y roles de las Fuerzas Armadas. RESI: Revista de Estudios en Seguridad Internacional, 4(1), 71-86.

Rosas Andreu, J. de. (2019). Una mirada a la evolución del concepto de derecho y la fractura de la "novela en cadena" en Ronald Dworkin. Revista de la Facultad de Derecho, 47. http://dx.doi.org/10.22187/rfd2019n47a15

Saint-Pierre, H. (2009). La defensa en la politica exterior de Brasil: El Consejo Suramericano y la Estrategia Nacional de Defensa [Documento de Trabajo, 50]. http://www.realinstitutoelcano.org/wps/portal/rielcano_es/contenido?WCM_GLOBAL_CONTEXT=/elcano/ elcano_es/zonas_es/dt50-2009

Share, D., \& Mainwaring, S. (1986). Transiciones vía transición: La democratización en Brasil y España. Revista de Estudios Políticos, 49, 87-136.

Soares, S. A. (2018). ¿Volvieron los militares en Brasil?: La democracia obstruida por la cuestión militar. Nueva Sociedad, 278, 48.

Vitelli, M. (2015). La identidad estratégica de Brasil: Política de defensa para un jugador global. Colombia Internacional, 85, 141-169. 